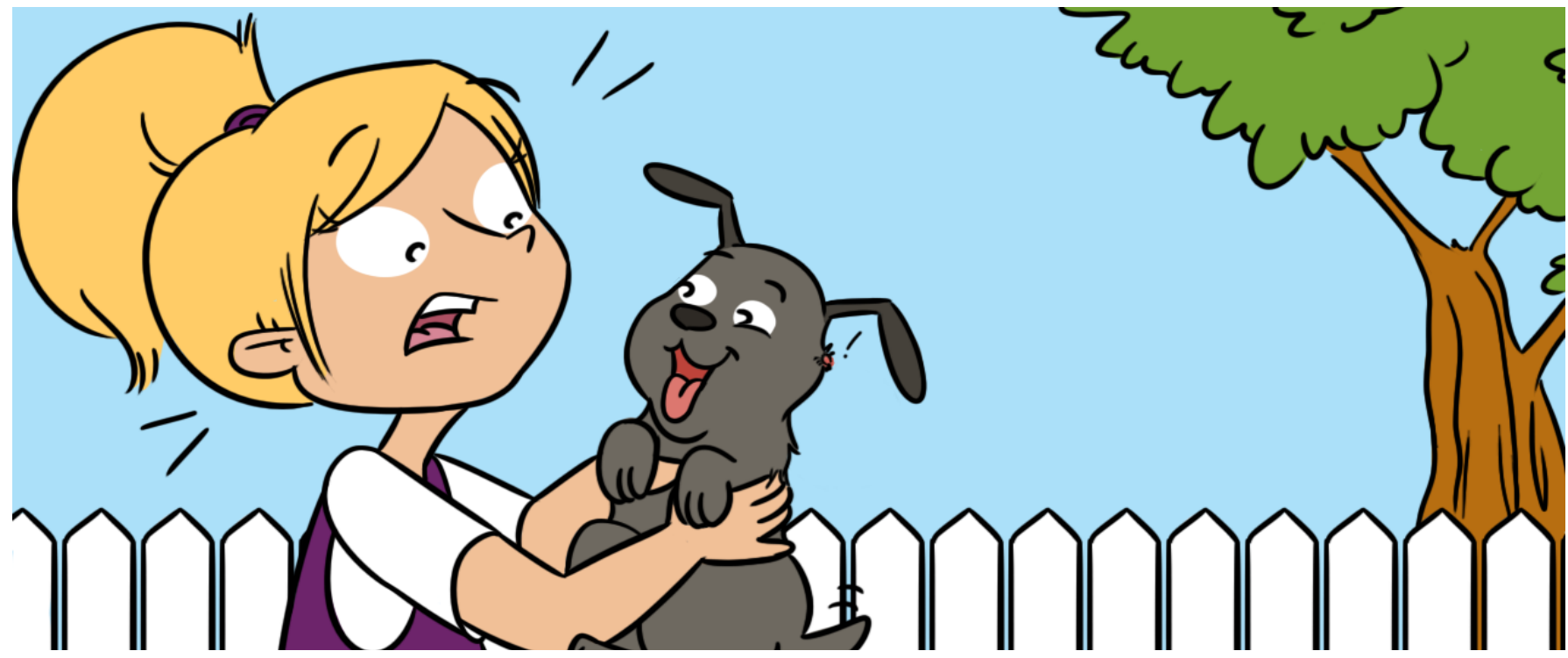

\title{
THE SECRET LIFE INSIDE TICKS
}

\section{Joana Ferrolho*, Joana Couto, Gustavo Seron Sanches, Sandra Antunes and Ana Gonçalves Domingos}

Global Health and Tropical Medicine - Instituto de Higiene e Medicina Tropical, Universidade Nova de Lisbon (GHTM-IHMT-UNL), Lisbon, Portugal

\section{REVIEWED BY:}

LIZA

AGE: 9
Have you ever noticed those nasty, awful, crawling, eight-legged, tiny bugs called ticks? If you own a dog or a cat or a turtle or a rabbit or a parrot or a horse or a cow or a piglet or even a snake, maybe you can recall seeing these parasites. If not, do not despair just Google ticks to see what they look like! Ticks really love to use our pets as restaurants. Well, almost all pets... If you have a fish, it is fairly safe! Since you and I are animals, even our blood can serve as a snack! If this was not bad enough, these little bloodsuckers can transmit several microbes that may or may not make us or our animals sick. All animals (ticks, humans, cats, dolphins, penguins, etc.) have millions of microbes living inside them, of which some are harmless, some can help the organism to function better, and some can be dangerous. When the tick bites you and has a blood meal, the microbes in the tick can move to a new and exciting neighborhood: you. Ok, let us not be so dramatic! Ticks do prefer animals besides humans that are less sensitive to parasites crawling up their legs... If you want to learn more about the secret life inside ticks, just keep reading. This little bit of information can be very useful... 


\section{ECTOPARASITES}

Parasites that live outside the host, for example, on the skin or hair.

\section{FIGURE 1}

Tick acting as a bus to transport protozoa, bacteria, and virus. Ticks can attach to animals and humans.

\section{TICKS ARE "LITTLE BUSES" OR VEHICLES FOR DISEASE-CAUSING MICROBES}

Ticks are ectoparasites, parasites that live outside the body, and live in practically all regions of the world. So far, approximately 900 tick species have been identified, but only a small number are known to carry microbes that can cause disease, which we call "disease-causing microbes." Examples of disease-causing microbes are bacteria and viruses [1]. These microbes are carried inside the tick's body (see Figure 1), using it as a way of transport, like a car or a bus, so that the microbes can be transmitted to many wild and domestic animals, as well as to humans.

\section{ARE THESE DISEASE-CAUSING MICROBES DANGEROUS?}

Not all ticks carry disease-causing microbes, only a small number of ticks actually do. Generally, these microbes do not cause the ticks to suffer any pain, or give them any signs disease. Ticks do not even realize that they are giving a lift to disease-causing microbes inside their bodies. So, these diseasecausing microbes are not dangerous for the ticks. On the other hand, if these

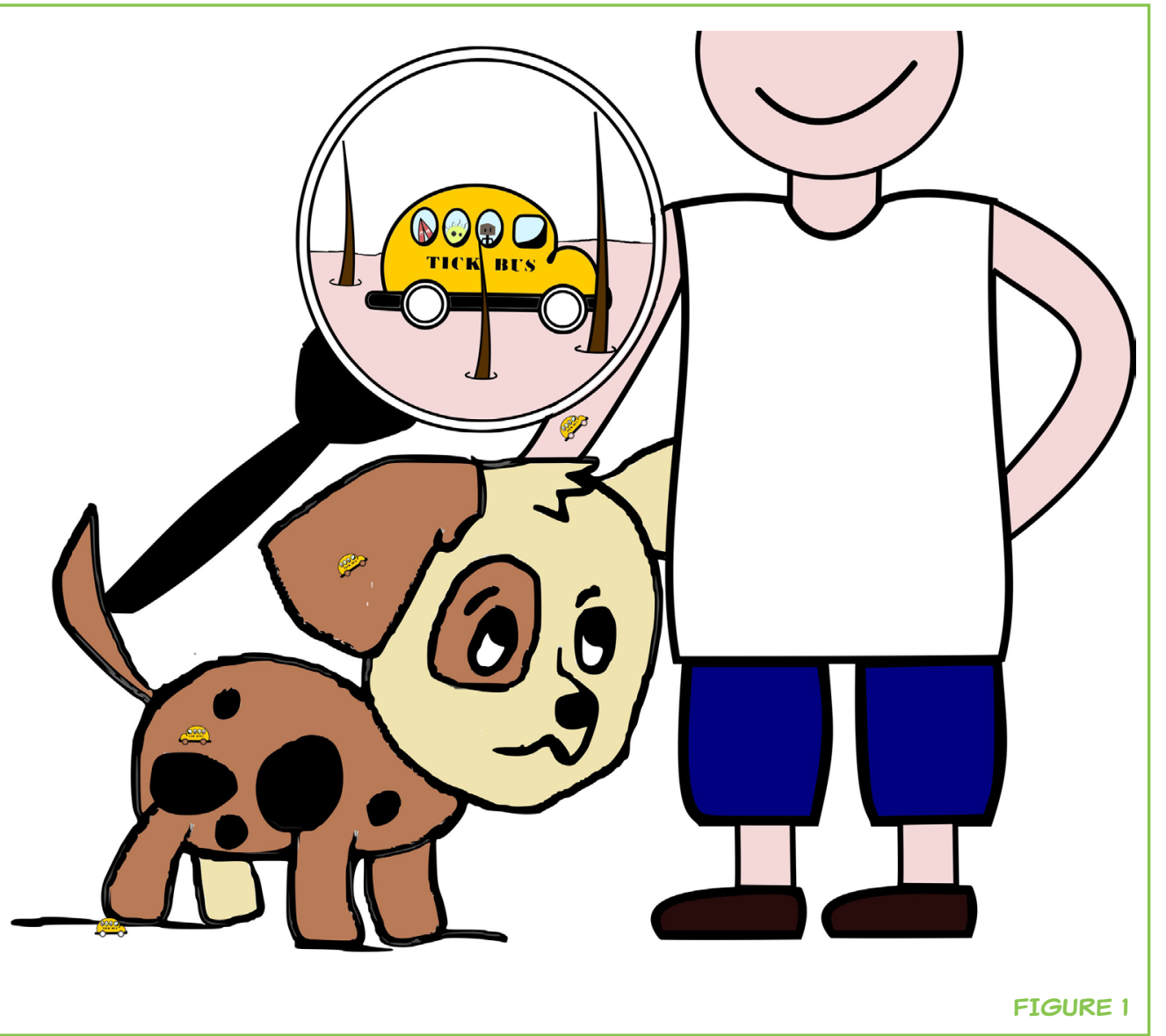




\section{VERTEBRATE}

Species of animals that have a vertebral column (back bone).

\section{HOST}

A human, domestic or wild animal or plant on or in which a parasite or other organism lives and obtains nutrients and/or shelter. disease-causing microbes are transmitted to wild or domestic (tame) animals, or even humans, they may cause diseases that can damage the animal or human's health very badly or even cause death [2]. In these cases, yes, the disease-causing microbes transmitted by ticks can represent a health danger. Like any rule, there are some exceptions. For example, some of the diseasecausing microbes are less aggressive and only cause a mild disease or do not cause any symptoms at all.

\section{HOW CAN THESE DISEASE-CAUSING MICROBES "GET A LIFT" FROM TICKS AND HOW ARE THEY TRANSMITTED TO AN ANIMAL OR TO US?}

To understand how disease-causing microbes get inside a tick to "have a ride," and how they are transmitted from the tick to an animal (including you and me!), it is important to understand the feeding habits of ticks. Ticks survive, develop, and reproduce using the nutrients and energy provided by blood meals [3]. Ticks only ingest blood obtained from a vertebrate (vertebrates are animals with backbones), including mammals, reptiles, birds, etc. Ticks live most of their time in the natural environment (vegetation, cracks of walls, etc.) and when they are hungry, they move around looking for an animal to feed on. That animal is called the host. Once the ticks find a host, they attach very strongly using their mouthparts, which penetrate the host's skin. If the ticks did not do this, they would be easily removed by the host when, for example, the host scratches, has a bath, or runs around. While they are attached, the ticks release saliva and start their blood meal. This stage is very important for the disease-causing microbes, because they take advantage of the saliva secretion and use the saliva as if they are surfing a wave, to move from the ticks' salivary glands (the organ where the saliva is produced) to the host. Also, because blood is mainly composed of water and ticks do not need much water, during the ingestion of blood the ticks regurgitate a big part of this water back to the host's blood stream, along with the microbes. This whole process is known as tick-host transmission. Once transmitted, the disease-causing microbe will reach the host's blood stream and invade organs like the liver or spleen, and in most cases cause disease. So, how do the disease-causing microbes get back into another tick? This happens when a tick feeds on an animal that has the disease-causing microbes, which then get ingested together with the host's blood.

Ticks ingest the host's blood, and in the blood, there are cells that contain the disease-causing microbes. We call them infected cells. Once the infected cells 


\section{HAEMOLYMPH}

Fluid that circulates inside of the tick's body, directly in contact with tissues and organs.

\section{PROTOZOA}

Group of organisms primarily made of one cell, that live alone or in colonies. They differ from bacteria because their genetic material is DNA in the form of chromosomes contained within a distinct nucleus. are ingested, their first stop will be the tick's guts, which function as the tick's stomach, where these microbes start their journey through the tick's body. Depending on the disease-causing microbe, they can stay in the guts shorter or longer periods of time, for example, for only a few hours, for days, or for weeks. From the guts, the microbes travel through the gut wall to go for a swim in a liquid called haemolymph. This liquid is rich in "little soldiers," the cells of the tick's immune system, which are constantly patrolling and preventing invaders from harming the tick. Some of these disease-causing microbes will die in the haemolymph, but others will continue their journey to the salivary glands (do you remember these? Where saliva is produced? The wave that microbes use to surf into the host's blood?), and still other microbes will reach the reproductive organs, including the eggs. These two last locations, salivary glands and eggs, are very important for the transmission of the disease-causing microbes to a host and to the next generation of baby ticks.

\section{CAN A TICK TRANSPORT MORE THAN ONE TYPE OF DISEASE-CAUSING MICROBE?}

A single tick can transport one or more disease-causing microbes as "passengers," most of the time without the health of the tick being affected by the presence of the microbes. Thus, a single tick can transmit one or multiple microbes to a host during the blood meal [4].

\section{SO, WHO ARE THESE TINY LITTLE DISEASE- CAUSING MICROBE PASSENGERS?}

Many kinds of microbes use the "super tick bus" to be transported into their new houses, the hosts. Each tick species can be compared with a bus line, each transporting different microbes to different destinations, humans or animals. Remember that different microbes can travel together on the same tick. For example, the tick Rhipicephalus sanguineus can transport many microbes, including the bacteria Ehrlichia canis, which can make dogs sick with a disease called Ehrlichiosis. In some parts of the world, R. sanguineus and other tick species can transport different bacteria that can cause, for example, a disease called Rocky Mountain Spotted Fever, which affects humans. Other kinds of microbes that use ticks to be transported are protozoa, which can affect domestic and wild animals, and occasionally humans. Protozoa are very small organisms which often live inside larger animals and are formed by only one cell. An important species of protozoa is Babesia bovis, which causes disease in cattle [2]. In addition, more than 38 species of viruses can use ticks as "buses" and threaten human and animal health [5]. These are just some examples of microbes that use ticks as vehicles, but there are many, many more. Be aware that a small tick bite can be a big problem for your health. Ticks that carry these disease-causing microbes do not look different 
from the ticks that are not carrying any microbes, they do not have green spots, red eyes, or grow alien heads or wings! Just from looking at the ticks you cannot tell the difference.

\section{FINAL KEY POINT}

Now that you have read this article about the microbes that ticks carry, the good and the bad ones, it is important for you to pass on this information to your friends and family. All of us should be aware of the importance of ticks as potential buses for dangerous microbes!

\section{REFERENCES}

1. de la Fuente, J., Antunes, S., Bonnet, S., Cabezas-Cruz, A., Domingos, A., Estrada-Peña, A., et al. 2017. Tick-pathogen interactions and vector competence: identification of molecular drivers for tick-borne diseases. Front. Cell Infect. Microbiol. 7(3):114. doi:10.3389/fcimb.2017.00114

2. Fritz, C. L. 2009. Emerging tick-borne diseases. Vet. Clin. North Am. Small Anim. Pract. 39(2):265-78. doi:10.1016/j.cvsm.2008.10.019

3. Sojka, D. 2015. Book review: Sonenshine D. E.; Roe R. M. 2013: Biology of Ticks. 2nd ed. Eur. J. Entomol. 112(3):564. doi:10.14411/eje.2015.069

4. Moutailler, S., Valiente Moro, C., Vaumourin, E., Michelet, L., Tran, F. H., Devillers, E., et al. 2016. Co-infection of ticks: the rule rather than the exception. PLoS Negl. Trop. Dis. 10(3):e0004539. doi:10.1371/journal.pntd.0004539

5. Mansfield, K. L., Jizhou, L., Phipps, L. P., and Johnson, N. 2017. Emerging tickborne viruses in the twenty-first century. Front. Cell Infect. Microbiol. 7:298. doi:10.3389/fcimb.2017.00298

SUBMITTED: 06 March 2018; ACCEPTED: 06 June 2018; PUBLISHED ONLINE: 27 July 2018.

EDITED BY: Fulvio D'Acquisto, University of Roehampton, United Kingdom

CITATION: Ferrolho J, Couto J, Sanches GS, Antunes S and Domingos AG (2018) The Secret Life Inside Ticks. Front. Young Minds 6:35. doi:10.3389/frym.2018.00035

CONFLICT OF INTEREST STATEMENT: The author declares that the research was conducted in the absence of any commercial or financial relationships that could be construed as a potential conflict of interest.

COPYRIGHT @ 2018 Ferrolho, Couto, Sanches, Antunes and Domingos. This is an open-access article distributed under the terms of the Creative Commons Attribution License (CC BY). The use, distribution or reproduction in other forums is permitted, provided the original author(s) and the copyright owner(s) are credited and that the original publication in this journal is cited, in accordance with accepted academic practice. No use, distribution or reproduction is permitted which does not comply with these terms. 

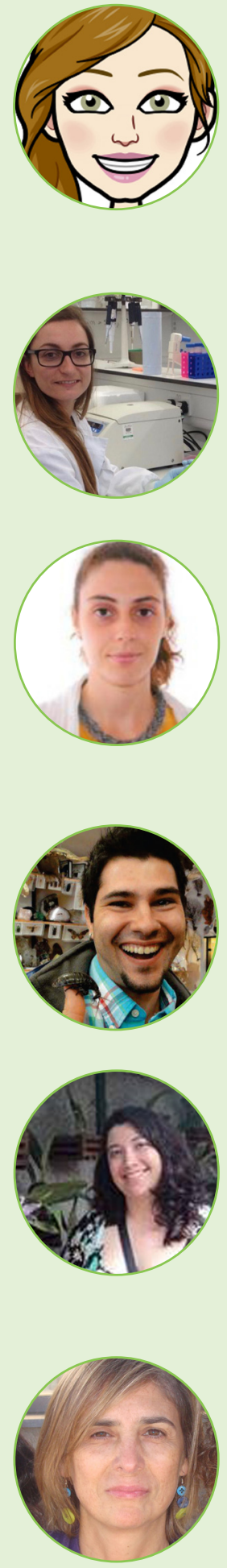

\section{REVIEWED BY}

\section{LIZA, AGE: 9}

I like art in school and out of school. I also like to work with computers. I recently read "A Wrinkle in Time" and I thought it was really good.

\section{AUTHORS}

\section{JOANA FERROLHO}

Joana Ferrolho is a Veterinary Surgeon doing a Ph.D. in Parasitology at Institute of Hygiene and Tropical Medicine in Lisbon, Portugal. Her Ph.D. is about discovering new molecules to use in vaccines against ticks and tick transmitted pathogens. After work, Joana enjoys spending time with her little son, read books, and play with her dogs. *joana.ferrolho@ihmt.unl.pt

\section{JOANA COUTO}

Joana Couto is a Biologist doing a Ph.D. in Molecular and Cellular Biology at Institute of Hygiene and Tropical Medicine in Lisbon, Portugal. Her studies are focused in the interactions between ticks and pathogens using tick cells, to identify molecules to block pathogen transmission or to control tick infestation and use them to design a vaccine. Joana loves to play with animals and go to the cinema.

\section{GUSTAVO SERON SANCHES}

Gustavo Seron Sanches is a Biologist currently working as a Postdoc at Institute of Hygiene and Tropical Medicine in Lisbon, Portugal. His work involves the characterization of differentstrainsof the "kennel tick" and to find the differences between their molecules. During Gustavo's free time he likes to exercise, walk his dog, and travel around the world.

\section{SANDRA ANTUNES}

Sandra Antunes is a Biologist currently working as a Postdoc at Institute of Hygiene and Tropical Medicine in Lisbon, Portugal. She is working with tick species that affect sheep and cattle, investigating molecules that act during the tick's blood meal and when the tick has a pathogen in its organism. During her free time, Sandra likes to spend time with her two sons, to watch TV series, and to play with her cat.

\section{ANA DOMINGOS}

Ana Domingos is a Principal Investigator, working at Institute of Hygiene and Tropical Medicine in Lisbon, Portugal. Ana's main research interest includes the development of vaccines against ticks and tick transmitted pathogens. Currently, she supervises several M.Sc. and Ph.D. students and Postdocs who work in different projects. During her free time, Ana likes reading, going to plays, and practicing yoga. 